\title{
PENGEMBANGAN MULTIMEDIA INTERAKTIF MOBILE LEARNING PENGURUSAN JENAZAH
}

\author{
Muhamad Tri Panunggal Aprianto, Saida Ulfa, Arafah Husna \\ Jurusan Teknologi Pendidikan, Fakultas Ilmu Pendidikan, Universitas Negeri Malang \\ Jalan Semarang 5 Malang 65145 0341-574700 \\ Muhammadtripanunggal28@gmail.com
}

Article History

Received:20 Januari 2020, Accepted: 19 Agustus 2020, Published: 26 Februari 2021

\begin{abstract}
Abstrak
Teknologi diharapkan mampu dijadikan salah satu cara untuk memajukan Pendidikan di Indonesia. Tujuan pengembangan multimedia interaktif mobile learning pengurusan jenazah ini yaitu menghasilkan produk yang menarik, interaktif, menumbuhkan minat dan semangat belajar siswa, belajar tanpa hambatan dan dapat berperan dalam fleksibilitas belajar yang lebih personal dan layak digunakan. Produk Multimedia Interaktif mobile learning terdapat materi berupa dialog, teks, audio, video animasi dan gambar. Metode Penelitian yang digunakan yakni penelitian dan pengembangan dan pada pengembangan ini model yang digunakan berupa model Lee \& Owens. Penelitian ini menggunakan model dari pengembangan multimedia menurut Lee \& Owens dengan tiga tahap penyelesaian, yaitu assessment/analysis, design dan development. Hasil pengembangan Multimedia Interaktif Mobile Learning Pengurusan Jenazah ini mendapatkan respon positif serta layak digunakan
\end{abstract}

Keyword: Multimedia Interaktif, Mobile Learning, , Pengurusan Jenazah

\begin{abstract}
Technology is expected to be used as one way to advance education in Indonesia. The purpose of developing interactive multimedia mobile learning body management is to produce products, which are attractive, interactive, growing interest and the learning spirit of students, learning without barriers and can play a role in the flexibility of learning more personalized and worthy of use. The Mobile learning interactive Multimedia product contains both dialogue, text, audio, animated video and images. The research methods used are research and development and on this development model used in the form of Model Lee \& Owens. This research uses models from multimedia development according to Lee \& Owens with three stages of completion, namely assessment/analysis, design and development. Development Results Interactive Multimedia Mobile Learning Body Management is a positive response and worth using.
\end{abstract}

Keyword: Multimedia Interactive, mobile learning, Body Management 


\section{PENDAHULUAN}

Teknologi informasi dan komunikasi dapat dijadikan sebagai salah satu cara untuk meningkatkatkan taraf dan kualitas Pendidikan di Indonesia. Dengan adanya smartphone, merubah perkembangan di segala sektor, salah satunya smartphone android telah merevolusi pendidikan, mengubah sistem belajar dari pembelajaran tradisional menjadi pembelajaran dimana saja dan kapan saja (Ulfa, 2013). Pendidikan Kurikulum 2013 memiliki beberapa factor penunjang, dimulai dari faktor internal, kemudian factor eksternal dan adanya perbaikan pada pola fikir, pola fikir menjadi poin penting dalam Pendidikan, karena mampu mempengaruhi kualitas dari pendidikan. (Meitantiwi, Masykuri, \& Nurhayati, 2015).

Pendidikan Agama Islam memiliki arti yang cukup penting, perlu adanya pola pembelajaran yang lebih mengikuti perkembangan zaman, salah satu cara dengan memanfaatkan teknologi dalam pembelajaran sehingga dapat mengurangi penggunaan metode ceramah, yang dapat diperkaya menggunakan media pembelajaran sehingga dapat menekan proses keterampilan dan aktifitas pembelajaran (Darimi, 2017). Kajian fiqih yang sering di praktek di lingkungan masyarakat adalah tata cara pengurusan jenazah, dan tergolong aktifitas fardhu kifayah. Fiqih menurut bahasa adalah pemahaman. Menurut istilah, fiqih merupakan ilmu yang menjelaskan mengenai hukum-hukum syari'at Islam yang berkenaan dengan bagian yang ada pada kehidupan manusia yang belandaskan pada AlQur'an dan Al-Hadist. (Islami, Anisariza, \& Prasetyo, 2018). Orang islam mempunyai kewajiban terhadap muslim lainnya yakni membantu dalam proses pemakaman terakhir dimulai dari memandikan, mengkafani, menshalatkan, hingga menguburkan (Fatimah, Satria, \& Andriyani, 2019)

Berdasarkan observasi yang dilaksanakan, di SMK Taruna Bangsa Wagir, diperoleh hasil bahwa, masalah utama yang terjadi pada proses pembelajaran adalah pemahaman materi, perlu diadakannya media yang membuat pembelajaran menjadi lebih ringkas dan jelas. Tahap pertama dalam analisis adalah melakukan penelitian di lokasi (Observasi), dan mendapatkan hasil berupa, guru lebih cenderung bercerita dan penugasan, buku cetak menjadi media yang digunakan oleh guru saat proses pembelajaran, sehingga siswa kurang tertarik dalam belajar, cepat mengantuk, membosankan.

Multimedia interaktif mobile learning menjadi salah satu alternatif yang dapat dilakukan untuk dijadikan media dalam pembelajaran, dalam multimedia interaktif mobile learning terdapat kolaborasi dari beberapa aspek terpadu, seperti, teks, video, gambar, audio, media dan adanya interaksi antara pengguna dan alat yang digunakan, tidak hanya sekedar mendengar ataupun melihat namun dapat disesuaikan dengan kebutuhan pengguna. Menurut penjelasan yang disampaikan oleh (Sutopo, 2003) yang menerangkan bahwa Multimedia interaktif adalah media pembelajaran yang mana user diberi kebebasan untuk mempelajari apa yang diinginkan. Penelitian yang dilakukan oleh Tommy (2019) menghasilkan sebuah produk yakni Multimedia Interaktif berbasis android yang dilakukan pada siswa kelas X SMK pada materi aksara Jawa. Berdasarkan uji coba yang dilakukan, produk teersebut dinyatakan layak oleh ahli materi dan ahli media, dan mendapat tanggapan positif dari siswa. Sehingga dapat digunakan sebagai media pembelajaran dan dapat meningkatkan semangat belajar pada siswa.

Sejalan dengan penelitian yang dilakukan, Terdapat sejumlah pengkajian signifikan yang dilakukan oleh (Wahab, 2013) Tentang pengembangan multimedia untuk mendukung proses pembelajaran pendidikan Agama islam, terdapat beberapa Kesimpulan pada penelitian tersebut adalah Penggunaan media pembelajaran Pengurusan Jenazah dapat membantu keberlangsungan pembelajaran, dan mendapatkan respons positif yang bagus pada mata Pelajaran Pendidikan Agama Islam di SMK PGRI SEELAWI. Selain penelitian tersebut, terdapat penelitianyang telah dilakukan, (Pulungan, Sahliah, Sarudin, \& Dharmawati, 2020) yang menerangkan bahwa, sebagian masyarakat muslim masih menganggap remeh terhadap Ilmu pengurusan jenazah, sehingga pembimbingan dan arahan harus dimulai agar dapat dipergunakan dimasyarakat. Pengurusan jenazah adalah tuntunan yang diajarkan oleh Rasulullah SAW. Perawatan jenazah adalah hak si mayat dan kewajiban bagi seorang muslim untuk melakukannya dengan pengurusan yang terbaik (Mohamed, 2008) 
Mobile learning memanfaatkan perangkat bergerak gawai (perkakas kecil, seperti mesin, yang memiliki fungsi) dan dapat dilakukan secara online maupun offline. (Susanto \& Akmal, 2019). Teknologi mobile memberikan kontribusi pengalaman belajar yang berbeda dan memiliki kualitas yang baik untuk siswa, Mobile learning dapat meningkatkan fleksibilitas belajar menjadi kegiatan yang lebih personal (Kurniawan, 2018)

Mobile learning dapat menjadi sebuah substitusi untuk memecahkan persoalan dalam pembelajaran, dan menjadi salah satu bentuk pemanfaatan inovasi dalam dunia pendidikan. sehingga mobile learning menjadi media pembelajaran yang interaktif dan tidak ada batas baik ruang ataupun waktu. Siswa di SMK Taruna Bangsa Wagir Malang diperbolehkan membawa ponsel smartphone ketika di dalam sekolah dan hanya dimanfaatkan untuk pembelajaran. sehingga menjadi satu langkah pengembang untuk mengembangkan media pembelajaran di sekolah tersebut.

Berdasarkan hal tersebut maka penggunaan multimedia interaktif mobile learning sebagai sarana Pembelajaran dapat disesuaikan dengan kebutuhan dan kemampuan belajar yang dimiliki oleh individu penggunanya, dengan konsep pembelajaran mobile learning yang memanfaatkan tersediaan materi yang bisa diakses dimanapun dan kapanpun. tujuan dari mengembangkan Multimedia interaktif mobile learning ini yakni sebagai pembelajaran inovatif yang yang proses pembelajarannya mengajarkan long life learning, Hal ini dapat membentuk siswa menjadi lebih kreatif, mandiri dalam proses belajar dan menghemat waktu.

Pengembangan ini bertujuan untuk menghasilkan produk Multimedia Interaktif Mobile Learning Pengurusan Jenazah, yang menarik, interaktif, menumbuhkan motivasi belajar siswa, belajar tanpa ada batasan, hambatan dan dapat berperan dalam meningkatkan fleksibilitas belajar menjadi kegiatan yang lebih personal dan berpusat pada siswa yang layak digunakan dan disesuaikan dengan kebutuhan siswa. Hal ini sesuai dengan penjabaran yang disampaikan oleh Ramadhan (2019) bahwa mobile learning memiliki tiga fungsi dalam kegiatan belajar di kelas (classroom instruction) yakni sebagai supplement (Tambahan), pilihan (opsional), pelengkap (komplemen), atau sebagai pengganti (Substitusi).

\section{METODE}

Model Penelitian yang digunakan termasuk dalam penelitian dan pengembangan yang sistematis, dengan metode pengembangan yang digunakan. model pengembangan yang digunakan menggunakan model dari (Lee \& Owens, 2004). yang sesuai dengan kebutuhan peneliti, diantaranya (1) Assesmentlanalysis yang terdiri dari 2 bagian utama yaitu analisis kebutuhan dan analisis Front-end; (2) Desain (Design); (3) Pengembangan (Development); (4) Implementasi (Implementation); (5) Evaluasi (Evaluation). Namun hanya dilaksanakan hingga tahap Development/Pengembangan karena masih dalam suasana wabah pandemic Covid19.

Pada tahap analisis dibagi menjadi dua bagian, yakni need assessment dan front and analysis, yang mana analisis kebutuhan (need assessment) merupakan suatu proses sistematis untuk melihat kesenjangan kondisi antara di lapangan dengan keadaan yang diharapkan. Dengan menentukan sikap dan tujuan, serta menentukan tindakan prioritas yang akan dilaksanakan. Front end analysis, teknik yang dilakukan sebagai jembatan dari kesenjangan yang ada antara keadaan nyata dengan keinginan yang diharapkan agar mencapai mufakat, yang terdiri dari: analisis, audiens, teknologi, situasi, tugas, kejadian penting, tujuan, masalah, media, data yang sudah ada dan biaya.

Tahap uji coba melibatkan subjek penelitian yang terdiri dari ahli media, ahli materi dan peserta didik. Tahap uji coba produk desain pembelajaran dilakukan oleh ahli media dan ahli materi untuk ditanggapi dan dilakukan revisi. Dimana ahli media adalah dosen di jurusan Teknologi Pendidikan Universitas Negeri Malang. Tahap uji coba Ahli materi dilakukan oleh guru agama Islam di SMK Taruna Bangsa Wagir, yang memiliki pemahaman materi agama yang mumpuni dibarengi dengan pengalaman mengajar di sekolah dan TPA selama 5 tahun. 


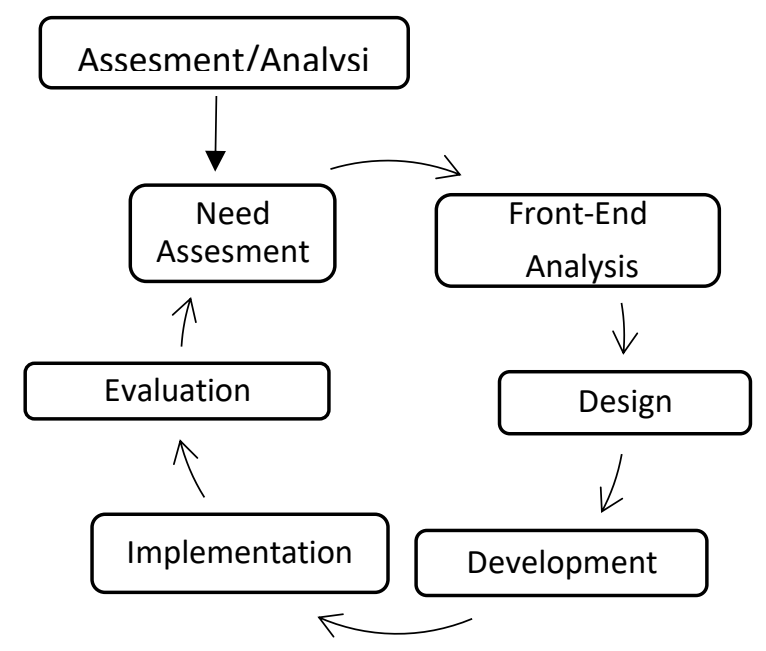

Gambar 1. Bagan Model Lee \& Owens

Setelah dinyatakan media layak, media pembelajaran diuji coba ke siswa untuk mendapatkan respon dan penilaian, uji coba dilaksanakan secara online via whatsapp dengan prosedur yang berlaku di masa pandemic Covid19. Subjek uji coba sebanyak 3 siswa yakni siswa SMK Taruna Bangsa kelas XI yang telah mendapatkan rekomendasi dari ahli materi yakni guru agama Islam.

Instrumen penelitian yang digunakan yakni tanggapan atau respon, dengan kisi kisi yang disediakan sebanyak 48 pernyataan untuk ahli media, dan 48 pernyataan untuk ahli materi. Ahli media memiliki berbagai aspek yang dinilai seperti, fungsi dan kemanfaatan media, aspek visual media, aspek audio pada media, tipografi, bahasa dan pemrograman media. Sedangkan dalam instrument untuk ahli materi meliputi identitas mata pelajaran, tujuan pembelajaran dan indikator, pemilihan materi, ketepatan bahasa, serta kualitas instruksional. Angket tanggapan yang telah terisi oleh ahli media maupun ahli materi memberikan gambaran tentang kelayakan media yang dikembangkan.

\section{HASIL}

\section{Need assessment}

Analisis kebutuhan atau (need assessment) dilakukan dengan cara yakni observasi secara langsung dan wawancara, agar mengetahui kondisi yang ada di sekolah. Observasi dilakukan agar dapat menentukan arah pengembangan dan menyesuaikan, menetapkan beberapa yang dibutuhkan dengan permasalahan yang terjadi di sekolah. Di dalam proses Pembelajaran dibutuhkan Multimedia interaktif mobile learning pengurusan jenazah, karena permasalahan yang terjadi yakni metode pembelajaran yang dilakukan oleh guru monoton, hanya ada interaksi satu arah media yang digunakan berupa buku cetak dan kurang menarik siswa dalam belajar berdasarkan hasil observasi langsung di sekolah.

\section{Front-end analysis}

Tahap analisis data yang telah dikumpulkan bertujuan agar mendapatkan informasi yang lebih aktual dan lengkap untuk produk yang akan dikembangkan, yakni (audience analysis) analisis siswa, berguna untuk melihat karakteristik siswa, (technology analysis) Analisis Teknologi, guna untuk mengidentifikasi kemampuan teknologi yang dimiliki oleh SMK Taruna Bangsa Wagir, (situation analysis) Analisis Situasi bertujuan untuk mengidentifikasi masalah dalam lingkungan belajar, taks analysis, critical analysis, objective analysis, issue analysis, media analysis, extand-data analysis dan cost analysis. Pada tahap pengembangan, menganalisis kondisi yang ada di SMK Taruna Bangsa, ketersediaan teknologi, karakteristik siswa, untuk tujuan pengembangan yang akan dilakukan dan meminimalisasi kesulitan pada saat penggunaan media yang dikembangkan. 


\section{Design}

Pada desain multimedia interaktif mobile learning terdapat menu utama, berupa beranda, tujuan pembelajaran, materi, pohon memori dan petunjuk penggunaan, Di dalam menu materi siswa dapat memilih materi yang ingin dipelajari, siswa dapat memilih materi berupa audio visual atau teks. dalam multimedia interaktif mobile learning ini terdapat evaluasi berupa pohon memori di mana setiap Siswa masing-masing memiliki kesempatan untuk membuat pohon memori secara mandiri sesuai dengan materi yang telah didapatkan, siswa dapat membuat pohon memori sesuai dengan keinginan dan tingkat pemahaman dari siswa. Pada tahap desain, media dikembangkan mengacu pada prinsip-prinsip multimedia Menurut Mayer (2009) multimedia merupakan penyampaian materi dalam bentuk kata-kata sekaligus gambar-gambar, Prinsip Multimedia, Seseorang akan lebih mudah dalam belajar ketika terdapat gambar dan kata, dibandingkan hanya kata atau kalimat. Prinsip Kesinambungan Spasial, Peletakkan gambar yang berhubungan secara dekat akan memudahkan seseorang dalam belajar dibandingkan keitka diletakkan secara berjauhan. Prinsip Kesinambungan Waktu, Seseorang akan belajar dengan mudah jika teks dan gambar yang berhubungan ditampilkan secara bersamaan dibandingkan sebaliknya. Prinsip Koherensi, orang lebih mudah belajar ketika kata-kata, suara, gambar, animasi, dan video yang tidak perlu atau tidak berhubungan sebaiknya tidak digunakan. Prinsip Modalitas Belajar, orang lebih mudah belajar dari animasi yang dilengkapi narasi (termasuk video), daripada animasi yang dilengkapi teks di layar.

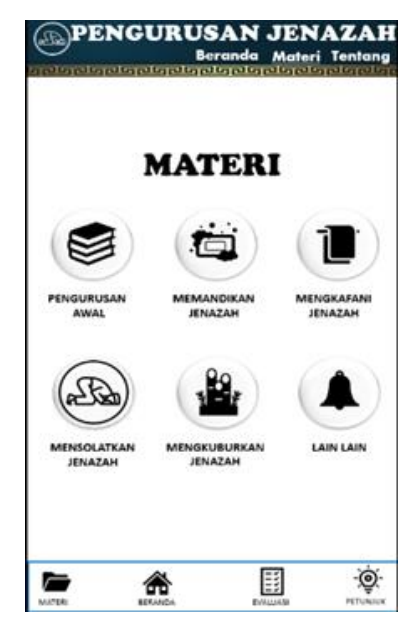

\section{Gambar 2. Tampilan Utama Aplikasi}

\section{Development}

Pada tahap pengembangan produk multimedia mobile learning ini menggunakan bantuan perangkat lunak untuk pembuatan produk yakni Microsoft PowerPoint, software pendukung dalam pengembangan yakni Adobe Illustrator CS6 untuk mengolah gambar dan After Effect untuk mengolah video animasi. Perangkat yang dibutuhkan saat menjalankan adalah handphone Android dengan spesifikasi Random Access memory (RAM) minimal 512MB agar tidak terkendala saat menjalankan.

Pada gambar 2 berupa contoh tampilan dari menu utama dalam aplikasi hasil pengembangan, di dalamnya terdapat beberapa pilihan materi, petunjuk penggunaan dan pohon memori, dimana, para siswa dapat menggunakan aplikasi tersebut sesuai dengan keinginan dan kemampuan. Setelah materi tersampaikan maka akan dibawa pada halaman pohon memori seperti yang ditunjukkan pada gambar. Siswa dapat memilih sendiri materi yang akan dipelajari, sesuai dengan keinginan siswa, setelah siswa menyelesaikan materi maka, siswa dapat membuat sebuah pohon memori sesuai dengan materi yang telah dipelajari 


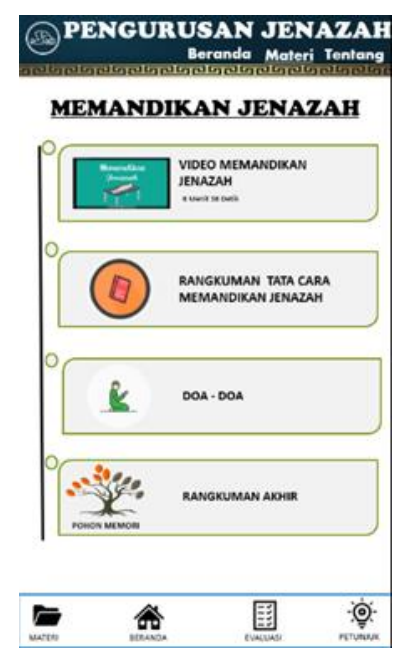

Gambar 3. Tampilan isi materi

Pada gambar 3 menunjukkan tampilan isi didalam tools materi dalam multimedia interaktif mobile learning pengurusan jenazah, terdapat tools yang dapat dipilih oleh siswa, berupa materi video animasi, terdapat pilihan dalam memilih materi, siswa dapat melihat materi berupa audio visual. Atau materi berupa teks, gambar dan audio, terdapat tools untuk mendengarkan doa-doa, doa doa dapat dipilih oleh siswa sesuai kebutuhan dan keinginan siswa dan siswa dapat memilih tools pohon memori untuk mengerjakan sebuah evaluasi sesuai dengan materi yang dipilih.

Pada tahap review yang dilakukan oleh ahli media dan ahli materi mengenai media pembelajaran ini diperoleh beberapa hasil yang disajikan pada gambar 4. Hasil Review yang didapatkan dari ahli materi menghasilkan rata-rata jawaban 3,5 dari 4,0 jawaban yang diharapkan. Terdapat 48 pertanyaan yang diberikan kepada ahli materi, 12 pertanyaan mendapat nilai 3 seperti yang terlihat pada gambar 4 . produk multimedia layak digunakan dengan beberapa catatan berupa koreksi tentang penambahan dan penjelasan materi, pemberian tambahan materi berupa video dan animasi.

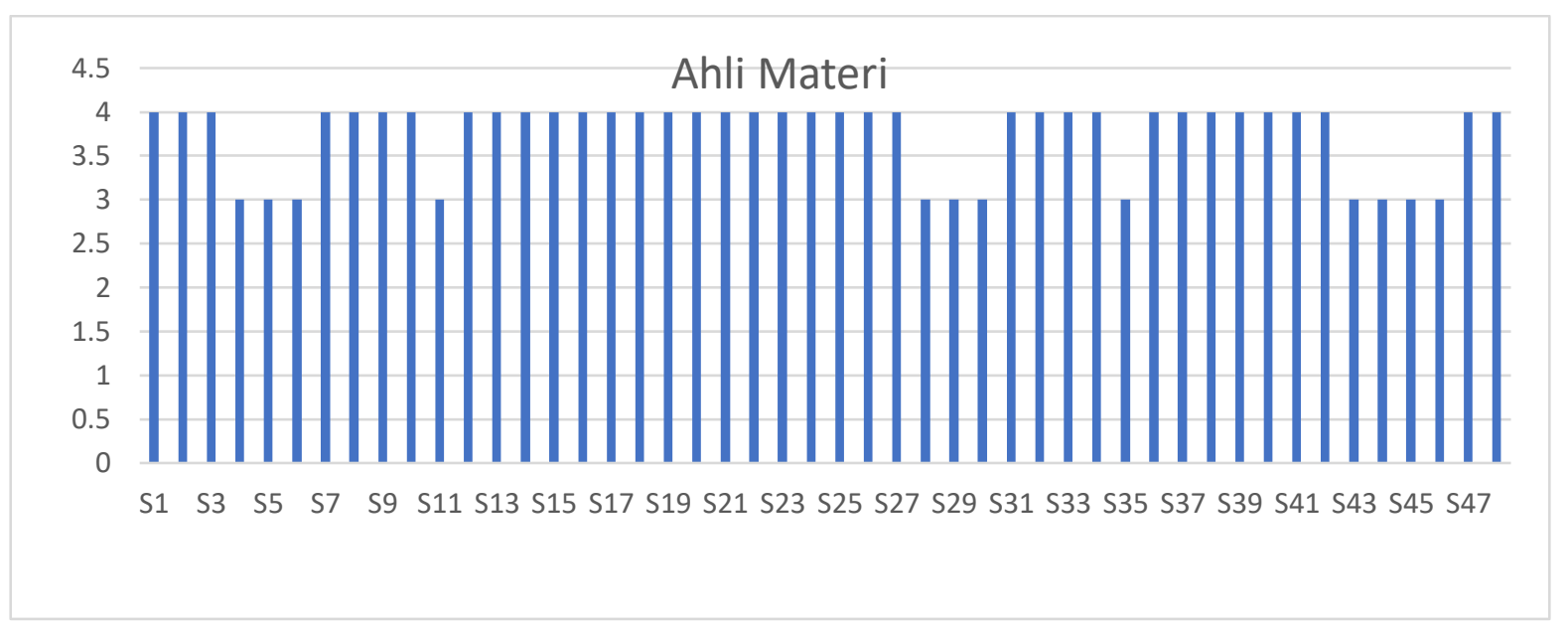

Gambar 4. Hasil Review Ahli Materi

Hasil review dari ahli media yaitu rata-rata jawaban 3,95 dari 4,0 jawaban yang diharapkan, Terdapat 15 pertanyaan yang mendapat nilai 3 dan 33 pertanyaan mendapat nilai 4 seperti yang terlihat pada gambar 5. secara keseluruhan ahli media memberikan tanggapan dan arahan yang positif, berupa tampilan desain dan minat penggunaan dari para siswa 


\section{Ahli Media}

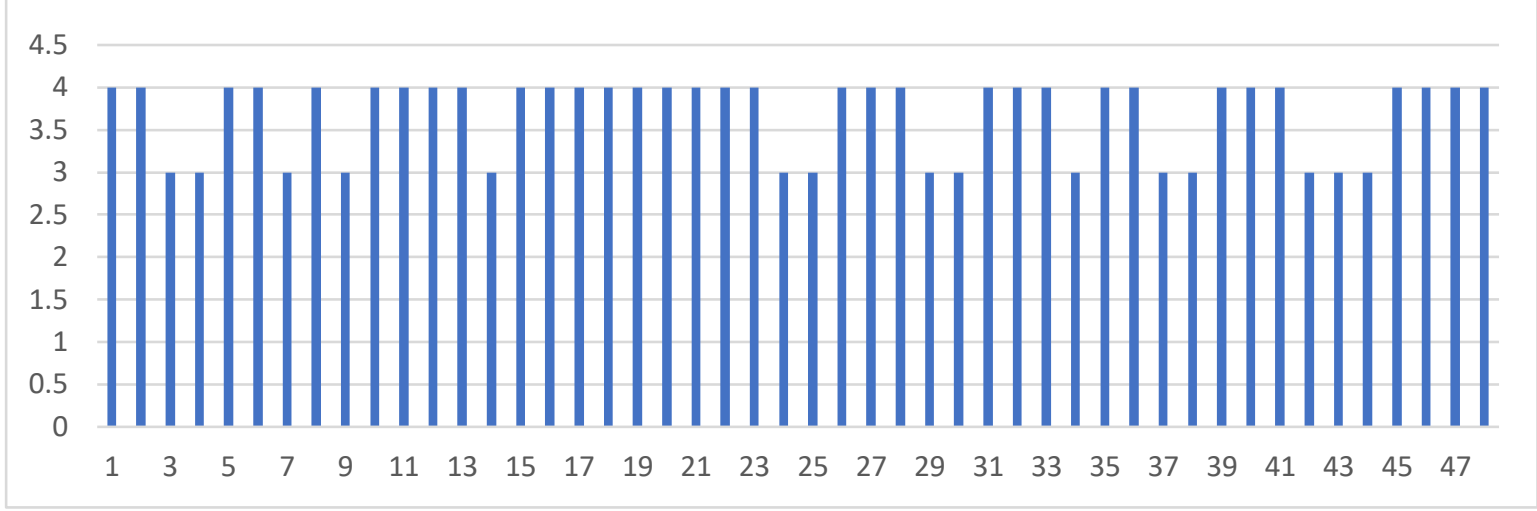

\section{Gambar 5. Hasil Review Ahli Media}

Produk diuji coba pada siswa kelas 11 SMK Taruna Bangsa sebanyak 3 siswa, dihasilkan bahwa produk dapat membantu dalam proses pembelajaran, tampilan media yang mudah digunakan, penyesuaian penyajian materi, dan juga kemudahan dalam mengaplikasikan media pembelajaran.

\section{PEMBAHASAN}

Multimedia Interaktif mobile learning telah melalui proses review yang dilakukan oleh ahli media dan ahli materi. Pada penelitian ini penilaian ahli materi dengan rata-rata 3,8 digunakan dengan perbaikan video animasi dan tambahan berupa materi memandikan jenazah dan mengkafani jenazah. Video Pembelajaran termasuk audio-visual yang dapat membantu dalam pembelajaran (Luhulima, Degeng, \& Ulfa, 2017). Pada butir S28 dan S29 yang masing-masing membahas tentang keakuratan informasi materi mendapatkan poin 3. Dalam pengolahan informasi yakni pengolahan verbal (teks dan suara) serta visual (gambar dan animasi) informasi akan cenderung mengarah pada penggunaan teks cerita visual yang relevan (Paivio \& Clark, 2006) Seseorang dapat lebih mudah dalam belajar ketika media pembelajaran memiliki dua gaya dalam belajar, yakni yang pertama visual, dan yang kedua verbal, hal ini akan menyebabkan informasi lebih mudah untuk diserap.

Ahli materi menjabarkan, terdapat materi yang kurang informatif dan harus disertakan dalam produk multimedia, seperti penegasan jumlah kain yang digunakan untuk mayit jika kain kafan sedikit, materi ini termasuk hal yang wajib diketahui sesuai dengan ketentuan syariat agama Islam (Al-albani, 2014), Pada butir S30 dan S35 juga mendapatkan poin yang rendah, yakni berkaitan dengan evaluasi pembelajaran yang terdapat dalam produk, dalam evaluasi ahli materi memberi saran berupa pembenahan dalam proses pembuatan evaluasi yang harus sesuai dengan tujuan pembelajaran. Hal ini karena evaluasi yang disajikan kurang memadai dan akurat sesuai dengan karakteristik siswa, penyesuaian dengan materi dan alat ukur untuk mengevaluasi. Evaluasi memiliki tugas yang penting dalam pembelajaran, akurasi data kemampuan atau kesulitan siswa sangat tergantung pada akurasi alat evaluasi dan proses evaluasi (Setemen, 2010)

Poin rendah juga didapatkan pada butir S40 tentang kemampuan mendorong berpikir kritis. Di karena kan pada produk media pembelajaran tidak disertakan permasalahan lebih lanjut agar siswa mampu secara individu maupun kelompok untuk berfikir secara kritis. Berfikir kritis dapat secara bertahap dilakukan oleh siswa yang dapat terus berubah, sehingga mampu meningkatkan pola fikir kreatif, inovatif, dan merangsang kinerja otak (Ristiasari, Priyono, \& Sukaesih, 2012). Secara menyeluruh produk pengembangan multimedia interaktif mobile learning mendapatkan tanggapan yang positif dan layak digunakan dalam pembelajaran berdasarkan hasil review yang dilakukan oleh ahli materi. Hal ini menunjukkan bahwa materi yang terdapat pada Multimedia nteraktif mobile learning pengurusan jenazah hampir memenuhi aspek review ahli materi sehingga layak dan dapat dipergunakan dalam proses pembelajaran. 
Penilaian yang dilakukan oleh ahli media dengan rata-rata 3,95 dan layak untuk digunakan, namun perlu memperjelas tampilan tombol dan font pada menu petunjuk penggunaan, ahli media berpendapat untuk memberikan warna yang cerah, tampilan desain yang dapat menarik siswa untuk menggunakan media, dan pemberian petunjuk yang mudah disampaikan. Beberapa poin yang rendah juga terjadi pada butir Ke 29 hingga butir 32, yang berkaitan dengan ketepatan dan kejelasan audio dan video dalam media pembelajaran juga mendapatkan poin yang rendah. Pada butir 29, Pernyataan tentang kejelasan intonasi suara/audio mendapatkan tanggapan nilai 3 , hal ini dikarenakan saat pengambilan suara, menggunakan alat perekam yang standar dan ketika mixing belum sempurna.

Pada Butir 30, mendapatkan nilai 3, tentang kejelasan video dan background video, Penggunaan background pada multimedia interaktif Mobile learning yakni warna putih dan bagian atas frame menggunakan warna biru tua, pada background didesain tanpa menggunakan gambar yang sangat ramai. sependapat dengan (Anas, Soepriyanto, \& Susilaningsih, 2018) yang menjelaskan bahwa pemilihan background polos adalah pilihan yang cukup tepat agar perhatian siswa lebih fokus pada materi yang disajikan. Butir yang terdapat di 31 dan butir 32 yang menjabarkan tentangkomunikasi dalam video, belum menekankan informasi yang komunikatif yang mudah dipahami. Kalimat yang terstruktur dan komunikatif dapat dengan mudah terserap dibandingkan hanya menggunakan kalimat yang baku (Mayer, 2009)

Terdapat beberapa komentar yang positif diberikan siswa, siswa suka belajar dengan menggunakan multimedia interaktif dan sangat interaktif menggunakan pohon memori, dengan adanya inovasi berupa pohon memori, diharapkan dapat mengasah daya pikir siswa dan kreatifitas, tujuan adanya inovasi dalam pembelajaran ini, diharapkan mampu memberi warna baru dalam dunia penididikan, dengan adanya inovasi dalam pembelajaran yang terstruktur dan memiliki tujuan dalam pembelajaran, dapat dijadikan sebuah solusi untuk menyelesaikan sebuah permasalahan (Subandijah, 1993).

Berdasarkan beberapa komentar menunjukan bahwa multimedia interaktif dalam pembelajaran dapat digunakan dan mendukung terjadinya proses pembelajaran yang lebih baik, secara interaktif, efektif, mandiri, maupun kelompok yang mudah dipahami, Pembelajaran yang efektif di tandai oleh adanya tahapan dalam ketercapaian siswa dalam pengalaman belajar yakni mencakup dua hal pokok, yaitu belajar aktif dan kualitas pembelajaran (Setyosari, 2014)

Hal yang sering terjadi dalam pembelajaran yakni guru hanya menjelaskan materi tidak menggunakan media dalam pembelajaran, akibatnya pembelajaran menjadi monoton dan kurang menarik. Dengan demikian pembelajaran belum menarik. Agar pembelajaran dapat di capai sesuai dengan tujuan maka harus ada inovasi dalam pembelajaran. Pembelajaran Inovatif adalah sebuah proses pembelajaran yang dapat memberikan doktrin, atau mengubah pemahaman materi pada siswa. Dengan adanya pembelajaran yang inovatif akan terciprta suasana yang kondusif yang dapat memaksimalkan proses pembelajaran, dan kreatifitas siswa (Nurdyansyah \& Widodo, 2015) Multimedia Interaktif didesain secara prosedural yang bertujuan untuk memahami dan memiliki pengetahuan tentang materi Pengurusan Jenazah, dimulai dari memandikan jenazah hingga menguburkan jenazah. Siswa diharapakan mengikuti dan terlibat dalam pembelajaran agar, menciptakan pembelajaran yang mengesankan, menjadikan informasi yang dapat dicerna, dan diimplementasikan di masyarakat.

Produk media pembelajaran yang dikembangkan saat ini hanya memiliki satu pokok pembahasan yang disesuaikan dengan kebutuhan belajar siswa dan tujuan pembelajaran. Multimedia interaktif ini memiliki kelebihan, multimedia interaktif dapat diakses di berbagai tempat dan waktu, dan tahan lama, Teknologi internet dan perkembangan teknologi smartphone melahirkan adopsi inovasi dalam berbagai bidang kehidupan manusia, salah satu yang muncul adalah istilah pembelajaran bergerak dalam bidang Pendidikan yang dikembangkan secara integratif (Surahman, 2019). Apabila dibandingkan dengan modul, dan buku teks yang mudah hilang dan rusak, multimedia interaktif dapat menarik minat siswa untuk belajar dan tampilan yang dinamis sesuai dengan karakteristik siswa.

Penggunaan media pembelajaran akan meningkatkan hasil belajar, aktifitas, dan motivasi siswa, yang dapat dijadikan sebagai pelengkap, pemelihara, hingga mampu untuk meningkatkan kualitas dalam 
proses pembelajaran (Susilana \& Riyana, 2008) Penelitian sebelumnya, tentang (Pengembangan Mobile Learning Berbasis Smartphone Android Materi Huruf Hiragana Pada Pelatihan Bahasa Jepang SMA Ma'arif NU Pandaan, 2018) mendapatkan respon positif, hasil uji coba yang lain yakni multimedia berbasis android juga mendapatkan respon positif dan layak (Amalia, Ulfa, \& Soepriyanto, 2020) pada pengembangan Multimedia Interaktif Untuk Belajar Penjumlahan dan Pengurangan Pecahan mendapatkan respon positif (Najib, Setyosari, \& Soepriyanto, 2018). Dengan demikian multimedia interaktif memiliki peluang yang besar untuk meningkatkan minat belajar siswa, dan memperbaiki proses dan kualitas pembelajaran. multimedia interaktif dapat diakses di berbagai tempat dan waktu, dan tahan lama, Teknologi internet dan perkembangan teknologi smartphone melahirkan adopsi inovasi dalam berbagai bidang kehidupan manusia, salah satu yang muncul adalah istilah pembelajaran bergerak dalam bidang Pendidikan (Surahman, 2019).

\section{SIMPULAN}

Berdasarkan penelitian yang dilakukan, maka disimpulkan, penelitian ini menghasilkan sebuah produk media pembelajaran yang dapat diterapkan dan memudahkan siswa dalam proses pembelajaran, Antusias siswa sangat positif dan dapat menarik minat belajar siswa dalam proses pembelajaran. Multimedia Interaktif mobile learning menjadi salah satu alternatif dalam belajar. Dalam penerapan uji coba terhadap siswa SMK Taruna Bangsa Wagir, mendapatkan respon positif dan layak dipergunakan, didapatkan, 93.75\% dari ahli media dan 95,4\% dari ahli materi. Secara keseluruhan multimedia interaktif Mobile Learning Pengurusan Jenazah ini layak dipergunakan sebagai suplemen dalam pembelajaran. Produk tersebut dapat membantu siswa dalam memahami materi.

\section{DAFTAR RUJUKAN}

Al-albani, N. (2014). Fiqih Lengkap Mengurus Jenazah. Jakarta: Gema Insani.

Amalia, M. S., Ulfa, S., \& Soepriyanto, Y. (2020). Multimedia Tutorial Berbasis Android untuk Memudahkan Siswa Memahami Materi Mengenal Notasi Balok Kelas X Seni Musik. Jurnal Kajian Teknologi Pendidikan (JKTP), 3(1), 59-57.

Anas, M. A., Soepriyanto, Y., \& Susilaningsih. (2018). Pengembangan Multimedia Tutorial Topolagi Jaringan Untuk SMK Kelas X Teknik KOmputer dan Jaringan. Jurnal Kajian Teknologi Pendidikan (JKTP), 1(4), 307-314.

Darimi, I. (2017). Teknologi Informasi dan Komunikasi Sebagai Media Pembelajaran Pendidikan Agama Islam Efektif. Cyberspace: Jurnal Pendidikan Teknologi Informasi, 1(2), 111-121.

Fatimah, D. D., Satria, E., \& Andriyani, A. (2019). Rancangan Bangun Aplikasi Media Interaktif Fiqih Pengurusan Jenazah Berbasis Android. Jurnal Algoritma Sekolah Tinggi Teknologi Garut, 16(2), 177-181.

Kurniawan, H. (2018). Media Pembelajaran Mobile Learning Menggunakan Android. Jurnal Sistem Informasi dan Telematika, 8(1), 46-55.

Luhulima, D. A., Degeng, I. S., \& Ulfa, S. (2017). Pengembangan Video Pembelajaran Karakter Mengampuni Berbasis Animasi untuk Anak Sekolah MInggu. JINOTEP Jurnal Inovasi dan Teknologi Pembelajaran, 3(2), 110-120.

Mayer, R. E. (2009). Multimedia learning prinsip-prinsip dan aplikasi. Yogyakarta: Pustaka Pelajar.

Meitantiwi, E. Y., Masykuri, M., \& Nurhayati, N. D. (2015). Pengembangan Multimedia Pembelajaran Tutorial Menggunakan Software Macromedia Flash Pada Materi Sifat Keperiodikan Unsur Untuk Pembelajaran Kimia Kelas X MIA SMA. Jurnal Pendidikan Kimia (JPK), 4(1), 59-67.

Mohamed, A. M. (2008, April 20). Pembangunan Pembelajaran Berbantukan Komputer (PBK) Berasakan Web : Pengurusan Jenazah. Malaysia, Malaysia, Universiti Teknologi Malaysia .

Najib, M. B., Setyosari, P., \& Soepriyanto, Y. (2018). Multimedia Interaktif Untuk Belajar Penjumlahan dan Pengurangan Pecahan. Jurnal Kajian Teknologi Pendidikan (JKTP), 1(1), 29-34. 
Nurdyansyah, \& Widodo, A. (2015). Inovasi Teknologi Pembelajaran. Sidoarjo: Nizamia Learning Center.

Paivio, A., \& Clark, J. M. (2006). Dual Coding Theory and Education. Michigan: The University of Michigan School.

Pulungan, S., Sahliah, Sarudin, \& Dharmawati. (2020). Peningkatan Keterampilan Pengurusan Jenazah di MTs Ulumul Quran Medan. Qalamuna-Jurnal Pendidikan, sosial dan agama, 12(1), 25-35.

Rahardjo, Tommy; Degeng, I Nyoman Sudana; Soepriyanto, Yerry ;. (2019). Pengembangan Multimedia Interaktif Mobile Learning Berbasis Android Aksara Jawa Kelas X SMK Negeri 5 Malang. Jurnal Kajian Teknologi Pendidikan , 2(3) 195-202.

Ramadhan, M. S. (2019). Pengembangan aplikasi Mobile Learning Pada Mata Kuliah Pemrograman Client Server Untuk Meningkatkan Prestasi Belajar Mahasiswa. Jurnal Teknologi Informasi, 3(1), 106-113.

Ristiasari, T., Priyono, B., \& Sukaesih, S. (2012). Model Pembelajaran Problem Solving dengan Mind Mapping Terhadap Kemampuan Berpikir Kritis Siswa. Unnes Journal of Biology Education, 1(3), 34-41.

Santoso M.J, R. A., Kuswandi, D., \& Husna, A. (2018). Pengembangan Mobile Learning Berbasis Smartphone Android Materi Huruf Hiragana Pada Pelatihan Bahasa Jepang SMA Ma'arif NU Pandaan. Jurnal Inovasi dan Teknologi Pembelajaran (JINOTEP), 4(2), 138-142.

Setemen, K. (2010). Pengembangan Evaluasi Pembelajaran Online. Jurnal Pendidikan dan pengajaran, 43(3), 207-214.

Setyosari, P. (2014). Menciptakan Pembelajaran Yang Efektif dan Berkualitas. Jurnal Inovasi dan Teknologi Pembelajaran, 1(1), 20-27.

Subandijah. (1993). Pengembangan dan Inovasi Kurikulum. Jakarta: PT. Raja Grafindo Persada.

Surahman, E. (2019). Integrated Mobile Learning System (IMOLES) Sebagai Upaya Mewujudkan Masyarakat Pebelajar Unggul Era Digital. JINOTEP (Jurnal Inovasi Teknologi Pembelajaran), $5(2), 50-56$.

Susanto, H., \& Akmal, H. (2019). Media Pembelajaran Sejarah Era Teknologi Informasi (Konsep Dasar, Prinsip Aplikatif, Dan Perancangannya). Banjarmasin: Program Studi Pendidikan Sejarah Fakultas Keguruan dan Ilmu Pendidikan Universitas Lambung Mangkurat .

Susilana, R., \& Riyana, C. (2008). MEDIA PEMBELAJARAN; Hakikat, Pengembangan, dan penilaian. Bandung: CV WACANA PRIMA.

Sutopo, A. h. (2003). Multimedia Interaktif dengan Flash. Yogyakarta: Graha Ilmu.

Ulfa, S. (2013). Mobile Technology Integration into Teaching and Learning. IEESE International Journal of Science and Technology (IJSTE), 2(1), 1-7.

Wahab, P. A. (2013). Pembuatan media belajar tata cara mengurus jenazah berbasis Multimedia (untuk mendukung pembelajaran PAI. Bandung: Digital Library UIN Sunan Gunung Djati. Diambil kembali dari Pembuatan media belajar tata cara mengurus jenazah berbasis Multimedia (untuk mendukung pembelajaran PAI). 